\title{
DO CONTROLE SOCIAL À GESTÃO PARTICIPATIVA: INTERROGAÇÕES SOBRE A PARTICIPAÇÃO POLÍTICA NO SUS
}

\author{
FROM SOCIAL CONTROL TO PARTICIPATIVE MANAGEMENT: QUESTIONS ABOUT POLITICAL \\ PARTICIPATION IN THE SHS
}

Francini Lube Guizardi 1

Resumo Este ensaio procura discutir a participação política no SUS a partir da problematização das opções e concepções que orientam sua definição como controle social, operacionalizado por meio de mecanismos de representação de interesses. Desta forma, a intenção de promover uma reflexão sobre a participação política no SUS é remetida ao cotidiano institucional, como desafio de construção de modos de gestão participativos. O conceito de Política que adotamos se define não em termos de igualdade (formal) que se contrapõe às diferenças (sociais), mas como co-produção de realidade que se concretiza nas relações entre igualdade e diferença, como acesso e uso dos bens comuns, em sua capacidade indeterminada e aberta de criação de valor. Pensar a participação nestes termos significa tecer participações como possibilidade de instituir normas, e não apenas como controle da execução e fiscalização das normas existentes. A participação na saúde é pensada, deste modo, a partir do problema de constituição de uma política pública que consiga permanecer aberta e imprevisível, resguardando, contudo, condições materiais de igualdade. Nesse sentido, uma política pública que rompa com os mecanismos da soberania moderna ao incorporar em seus desenhos institucionais a imprevisibilidade da produção normativa, forjando-se como dispositivo ético de produção de valor.

Palavras-chave participação política; controle social; gestão participativa; políticas públicas.
Abstract This essay seeks to discuss political participation in the Single Health Service (SHS) based on the problematization of the options and conceptions that guide its definition as social control, made operational by means of mechanisms of representation of interests. As such, the goal was to drive reflection on how political participation in the SHS is transferred to daily institutional life, as a challenge to build modes of participative management. The Policy concept we adopt is defined not in terms of equality (formal), which opposes differences (social), rather as the co-production of a reality that is made concrete in the relationship between equality and difference, such as the access to and use of common goods, in its undetermined capacity, one that is open to the creation of value. Thinking of participation in these terms means to weave participation as the possibility to institute norms, and not only as the control of the execution and inspection of the existing norms. As such, participation in health is thought out based on the problem of constituting a public policy that can remain open and unpredictable, safeguarding, nonetheless, the material conditions of equality. In this regard, a public policy that breaks away from the modern sovereignty mechanisms by incorporating itself into its institutional design the unpredictability of normative production, becoming an ethical device for the production of value.

Keywords political participation; social control; participative management; public polices. 


\section{Introdução}

O melhor modo de apresentar a discussão que propomos neste artigo é retomar no título aquilo que explicita nosso problema de pesquisa. De partida, podemos dizer que é um convite ao deslocamento das noções que definem o que entendemos no Sistema Único de Saúde (SUS) por controle social em direção à gestão participativa. Esse convite nos pede, num primeiro momento, um exercício de estranhamento, já que quando falamos em controle social temos implícitos determinados conceitos do que seja a participação política, que não nos ajudam a operar esse deslocamento.

Em nossa perspectiva, para discutir a participação política no SUS e pensar criticamente suas possibilidades, precisamos problematizar as opções e concepções que restringem sua operacionalização estritamente por meio de mecanismos de representação. Por esta razão a reflexão que propomos sobre as possibilidades de participação política no SUS é remetida ao cotidiano institucional da gestão, uma vez que entendemos que o princípio de participação da comunidade diz respeito à constituição do próprio direito à saúde.

Ao falarmos em constituição, procuramos enfatizar sua apreensão não estritamente como garantia constitucional, formalização jurídica, mas como práticas de sociabilidade, princípios reguladores "que estruturam uma linguagem pública" (Telles, 1994, p. 92) e que ganham materialidade através da complexidade dos fluxos e movimentos societários. Nesse sentido, consideramos a conquista constitucional apenas uma faceta da construção efetiva da saúde como um direito, construção coletiva, que não pretendemos relativa a modelos ou metas a serem alcançadas, mas produção de realidades sociais. A noção de direito é aqui entendida como invenção política, não porque implica diretamente a instância estatal, mas porque presume a determinação de referências de sociabilidade, a constituição de territórios existenciais. Construção política do direito à saúde que faz do SUS espaçotempo primordial desse processo histórico-social e da participação política estratégia fundamental.

Contudo, tal como o direito à saúde não se define estritamente por sua explicitação constitucional, também a participação política, para ser efetiva na definição e gestão das políticas públicas de saúde, não depende apenas da existência formal das instâncias de controle social. Como nos mostra a literatura acadêmica sobre o tema ${ }^{2}$, particularmente no que diz respeito aos conselhos de saúde, é possível observar aspectos recorrentes na experiência de participação política no SUS. De modo geral, inúmeros obstáculos à concretização das principais expectativas a ela vinculadas têm sido atualizados, persistindo ao longo da trajetória de implementação destes fóruns. Dentre os principais problemas identificados, podemos destacar a dificuldade em 
reverter o padrão de planejamento e execução das políticas de saúde em direção à radicalização do projeto democrático. Aspecto principalmente pertinente à sua capacidade de determinar a produção das políticas públicas a partir das características locais e regionais e da experiência dos setores e grupos sociais implicados.

Tais questões demonstram que a intenção de vocalização dos interesses e de construção de estratégias de intervenção por grupos e setores usualmente segregados do plano institucional de deliberação política não tem se concretizado. Nesses 17 anos de experiência com os conselhos de saúde, hoje presentes em 5.580 municípios brasileiros (Brasil, 2008), tem-se constatado que a participação, principalmente do segmento dos usuários, tende a ser cerceada na medida em que a presença quantitativa assegurada com o requisito jurídico da paridade, mesmo quando cumprida, não significa uma correspondência direta com a capacidade de intervenção. Essa característica recorrente incide negativamente na eficácia dessa forma de participação, tolhendo-a em um de seus principais propósitos, qual seja a vocalização política da sociedade civil, particularmente dos grupos populares. Fator que nos permite perceber a existência de diferentes inserções nos conselhos de saúde. De fato, pretender uma igualdade a partir da presença física dos representantes seria supor que ela pudesse superar em si mesma um longo processo sócio-histórico engendrado através de inúmeras desigualdades. Podemos mencionar alguns dos aspectos que ajudam a conformar esse cenário: os artifícios de poder usados pelo discurso técnicocientífico; as dificuldades relatadas quanto aos mecanismos de representação; a tendência de reprodução do jogo político local em suas relações de força e exercício de poder; e a apropriação dos conselhos pelo poder executivo, com um consequente caráter monológico prevalecendo na dinâmica desses espaços.

Nesse sentido, as questões trazidas sobre a concretização do controle social nos conselhos de saúde apontam-nos um debate necessário sobre a eficácia (deliberativa) dos dispositivos ${ }^{3}$ institucionais de participação política hoje existentes no SUS. Remetem-nos, sobretudo, à discussão sobre a construção e articulação de novos recursos e artifícios de participação que expressem a diversidade das experiências e posicionamentos implicados na produção das políticas de saúde. Isto porque o princípio de participação da comunidade supõe que a constituição da política seja porosa às demandas, realidades e 'fazeres' dos diferentes agentes e grupos sociais, possibilitando não somente a atualização das formas já instituídas do direito à saúde, mas também a expressão de seus movimentos constituintes. Em outros termos, propomo-nos a discutir o problema da participação como pertinente à produção das políticas públicas e, portanto, como relativo à constituição do próprio direito à saúde. 
Em nossa compreensão, esse desafio não trata, exatamente, de fazer o político corresponder ao social, mas de "inserir a produção do político na criação do social" (Negri, 2002, p. 425), de afirmar a dimensão política da ação como as possibilidades e usos feitos na produção de realidades sociais. Pois, como coloca Arendt (1998), o sentido da política é a liberdade, a liberdade de produção do novo, razão pela qual qualificamos como sendo política a participação que esperamos ver no SUS. Sem questionar como tem sido compreendida e concretizada esta participação, pensamos que dificilmente esses obstáculos serão superados, já que seu enfrentamento exige não apenas intervir nos efeitos que geram, mas também em seus regimes de produção, nos entrelaçamentos e determinações que os atualizam em tão diversas circunstâncias. Questão que remete à configuração das instituições de saúde, ao modo como se organizam expressando lógicas materializadas em relações e equipamentos sociais, em tecnologias específicas de governo. Colocar neste plano o problema da participação política no SUS consiste em aceitar o desafio de criar novas alternativas e também de reinventar as já existentes, de aproximá-las das expectativas éticas de democratização social que o direito à saúde expressa e mobiliza.

De modo algum negligenciamos os avanços conseguidos com a conquista dos fóruns institucionalizados de participação. Ao contrário, entendemos que a necessária e desejada eficácia desses espaços depende da capacidade de radicalizar o projeto democrático, da capacidade de pensar a participação na construção e gestão cotidiana da política de saúde, porque é na dinâmica do funcionamento dos serviços que concretamente a população vive como realidade material o direito à saúde.

É preciso, contudo, observar que os limites que encontramos em pensar a participação política no SUS para além dos mecanismos de representação não fazem parte apenas da realidade do sistema de saúde e da organização sociopolítica brasileira. Eles remetem, antes, à constituição do próprio Estado e das formas hegemônicas de institucionalização da ação política. Sem compreender essas vinculações é muito difícil debater o que desejamos construir como materialização do princípio de participação da comunidade no SUS e propor alternativas à sua concretização.

\section{Constituição das formas hegemônicas de inserção e participação política}

Para compreender as formas hegemônicas de inserção e participação política, é necessário retomar os fundamentos e mecanismos de efetivação da soberania, principalmente no que diz respeito aos preceitos do estado de direito, que se configura a partir da contestação por parte de diversos movimentos revolucionários, da personificação histórica do poder estatal na 
figura do monarca. A contraposição derivada desses embates não resultou realmente na desmontagem da estrutura absoluta do poder estatal, tampouco dos seus recursos administrativo-institucionais ou do sentido de racionalidade e finalidade de suas intervenções. Em verdade, todas essas características viriam a ser aperfeiçoadas e superdimensionadas com a organização do Estado Moderno. Ocorreu, outrossim, afirmá-los em função de valores que não a referida personificação histórica: valores apresentados como pertencentes ao indivíduo, em função de que este passa a ocupar o lugar de "protagonista direto da vida civil e política" (Schiera, 1998, p. 430). Como expuseram Negri e Hardt (2001, p. 105), "por meio dessas operações da máquina de soberania, a multidão se transforma, em todos os momentos, numa totalidade ordenada". Uma totalidade de indivíduos, uma nação.

Assim, o Estado organiza-se como Estado de garantias, frente ao qual a participação política, o agir político em sua dimensão ontológica, é resolvido como sendo pertinente ao âmbito das liberdades individuais, já que o indivíduo se faz fonte da legitimidade estatal. Formalização que apenas foi possível ao recorrer a referências lógicas e abstratas, portanto externas e inobjetáveis: as normas jurídicas, por meio das quais é instituída a igualdade de todos os indivíduos perante o Estado. Como salienta Schiera (1998), passa-se assim da legitimidade à legalidade, operação fundada

(...) sobre a liberdade política (não apenas privada) e sobre a igualdade de participação (e não apenas pré-estatal) dos cidadãos (não mais súditos) frente ao poder, mas gerenciado pela burguesia como classe dominante, com os instrumentos científicos fornecidos pelo direito e pela economia na idade triunfal da Revolução Industrial (Schiera, 1998, p. 430).

Fundamentado na legalidade desses preceitos, o estado de direito legitima-se com a construção de uma esfera pública enraizada na igualdade formal dos indivíduos-cidadãos, igualmente submetidos ao aparelho jurídico estatal. A separação, com isso, instituída entre esfera pública (plano político dos direitos) e sociedade privada, passa a exercer-se como baluarte do imperativo da representação dos interesses individuais (privados) frente à instância estatal. A liberdade de participação política delimitada neste contexto equivale, portanto, à liberdade das garantias individuais. O Estado faz-se 'externo' à sociedade, demarcando a moderna fronteira entre o que seria social e o que seria político.

Por outro lado, percebe-se facilmente que a igualdade que esta noção de cidadania pressupõe choca-se com a desigualdade real inerente ao processo de acumulação capitalista que se mostra a outra face da formação do Estado Moderno. A ambiguidade presente entre a formalização legal e a dinâmica societária real materializa-se no fato de que a res publica assim instituída 
revela-se referência maior aos "possuidores de bens: sejam eles terras, instrumentos de trabalho ou mercadorias" (Gerschman, 1995, p. 28). Como resultante, a representação política imposta pela separação formal entre esfera pública e sociedade 'privada' produz como efeito indiscutível a cristalização de dispositivos de poder que buscam usurpar a potência ontológica do agir político dos homens de sua prerrogativa de constituição de mundo, fechando-a nas amarras da divisão social do trabalho.

Deste modo, o poder constituinte é absorvido na máquina pela representação. O caráter ilimitado da expressão constituinte é limitado em sua gênese, porquanto submetido às regras e à extensão relativa do sufrágio; no seu funcionamento porquanto submetido às regras parlamentares; no seu período de vigência, que se mantém funcionalmente delimitado, mais próximo à forma da ditadura clássica do que à teoria e às práticas da democracia: em suma, a ideia de poder constituinte é juridicamente pré-formada quando se pretendia que ela formasse o direito, é absorvida pela idiia de representação quando se almejava que ela legitimasse tal conceito (Negri, 2002, p. 11).

Eis porque a representação tem-se construído como monumento dessa contradição: por confrontar a igualdade formal à desigualdade real, fissura erguida na inacessibilidade de diversos grupos sociais à res publica (agora sinônimo de esfera estatal) da construção política. Alijamento que se efetiva por meio dos mecanismos de regulação do poder constituinte imanente à vida, separada do político e feita espaço próprio do social. O campo da representação é então batizado como prática política por excelência, força maior de expressão dos poderes 'do cidadão', cujo exercício político fica desta forma confinado, num território próprio e distante de seu fazer cotidiano. A política é esvaziada de sua dimensão ontológica, salvaguardada da contaminação intempestiva do desejo, tornada prática exclusiva da chamada classe política. As demais convertem-se, assim, em meras classes sociais. Em suma, ao colocar-se como mecanismo de mediação frente a separação formal entre esfera pública e sociedade 'privada', a representação política produz como resultado a restrição da potência ontológica do agir político dos homens em sua prerrogativa de constituição de mundo. O espaço público não é vivido como território aberto à produção de realidade social, mas como espaço de sua regulação, de sua contenção, enredado em redes hierárquicas e institucionais de ordenamento social. O que pretendemos colocar em questão, portanto, é a própria compreensão da dimensão política da atividade humana, para o que utilizamos como referência o conceito de Agamben (2004) de estado de exceção.

Este autor propõe pensar o estado de exceção como fundamento da política moderna, presença recorrente na história de todos os Estados- 
nação. Em suas pesquisas, ele mostra como esse recurso jurídico marcou os momentos mais decisivos da história ocidental, sendo usado com tal recorrência que nos permite ver que não se trata realmente de uma exceção, mas de um mecanismo sempre presente nos regimes constitucionais. O estado de exceção pode ser descrito como a suspensão do ordenamento legal, geralmente feita em detrimento das garantias e direitos constitucionais individuais. É um dispositivo jurídico fundado nos marcos do paradigma da segurança e que tende a se tornar regra com a ampliação da biopolítica como tecnologia de poder.

A modernidade é, portanto, marcada pela tentativa de incluir a exceção na ordem jurídica, o que implica estabelecer uma zona em que fato e direito não se diferenciam: fato se transforma em direito e, inversamente, o direito é suspenso como fato. Por isso, no estado de exceção a relação com a ordem jurídica não é efetivada por meio de nenhum conteúdo normativo, mas pela relação de forças que o estado de exceção institui (e assegura) entre norma e realidade. O que une norma e exceção é a garantia de sua aplicação, do exercício do poder que as funda. Em outros termos, entre ambas há uma vinculação comum com a realidade, na medida em que se constituem como 'normatização efetiva do real'.

Essa vinculação com a exceção característica do ordenamento estatal traz à tona a dissociação intransponível entre norma jurídica e realidade. Dissociação que só pode ser silenciada com o recurso à força, já que não há nada interno à norma que garanta sua aplicação. Ao contrário, a norma jurídica se funda na suspensão do poder normativo da práxis (ação histórica) como ação imanente ao real. "Desse modo, a união impossível entre norma e realidade, e a conseqüente constituição do âmbito da norma, é operada sob a forma da exceção, isto é, pelo pressuposto de sua relação" (Agamben, 2004, p. 63). A exceção é, em última instância, um mecanismo essencial para restringir suas possibilidades normativas da vida e assegurar a relação entre norma jurídica e realidade. Não nos surpreende que na estrutura do Estado-nação, os direitos de cidadania das constituições democráticas são condicionados pela inscrição da vida em sua relação com o território (localização) e o ordenamento (Estado).

A discussão colocada por Agamben nos interessa porque explicita uma questão que consideramos fundamental: o fato de que a modernidade pretende fundar a experiência política como inscrição da vida no ordenamento estatal. O que significa dizer que os dispositivos que se articulam com o Estado Moderno têm como perspectiva a expropriação da potência ontológica do agir humano. Talvez essa seja a interface mais clara da relação entre política, vida e Estado. Porém, ao contrário do autor, achamos necessário destacar que a experiência política, embora tenha sido constrangida a assumir determinada expressão no Estado Moderno, não pode ser de forma 
alguma reduzida a seus mecanismos e efeitos de apropriação e codificação. Isto porque, como discute Foucault (1988), não são os corpos o objeto último do poder, e sim as ações, a conduta humana. Ou seja, o poder só existe como exercício, e por isso está situado definitivamente no plano da liberdade, da normatividade que caracteriza a vida.

O que pretendemos indicar é que a relação entre vida e soberania tem como solo de possibilidade justamente a liberdade. O limite do controle é a própria vida humana, o que torna o plano político o plano de emergência da liberdade. Nesse sentido, como diz Negri, é ao redor do problema da decisão que nasce o político (Negri, 2003). E é justamente essa condição limite da soberania, como bem a definiu o autor, que expõe o caráter falho dos mecanismos de objetivação da vida, em que pese sua indiscutível eficácia. Eficácia que exatamente por isto se apresenta entre parênteses, como produção e governo de subjetividades que, todavia, não pode eliminar sua dependência da existência da própria relação de poder.

Assim, divergimos de Agamben (2004) por considerar que entre a intenção desse exercício de poder e sua efetivação há a atividade humana, em sua impossibilidade de plena objetivação. Entendemos a atividade tendo por referência o modo como o conceito é trabalhado por Schwartz (2007), para quem a atividade é a perene tentativa de desneutralizar a relação com o meio, de procurar recentrá-lo segundo suas próprias normas.

O conceito de atividade expõe o desafio sempre colocado aos homens de viver e fazer história. O que significa dizer que a vida não pode ser contida no prescrito, no codificado, no instituído. Ela os extrapola, exatamente na medida em que exige do humano a criação, a reinvenção incessante de si. Prerrogativa ontológica que garante a todos ser e fazer história, a cada momento singular, sendo justamente essa dimensão do conceito que nos interessa, por auxiliar o entendimento da dimensão constituinte do agir que impede sua objetivação absoluta. De fato, os dispositivos de poder pretendem controlá-la, diminuir sua potência ontológica ao definir coletivos autorizados ao seu exercício e excluir a ação de outros como ilegítima, particularmente através dos mecanismos de representação. Seria essa a "fratura biopolítica essencial" (Agamben, 2004) do estado de direito, que procura capturar todo o espaço de 'anomia', lido aqui não como negatividade, mas como possibilidade de constituição de novas e outras normas.

Essa análise não pretende advogar a impossibilidade de constituir o direito a partir da atividade humana, da qual emerge o plano político. O que se pretende salientar é o fato de que a história política do Ocidente teve como solo e horizonte tal "fratura biopolítica fundamental", que tem como maior edifício o Estado Moderno, mesmo quando nomeado como democrático. Por isso defendemos que o objetivo de problematizar as perspectivas da 
participação política no SUS deve partir do desafio de restituir a vida, em sua prerrogativa normativa, como o espaço do político.

Quanto a isso, pensar a participação política como restrita a mecanismos de representação equivale a objetivar os homens em suas relações de co-existência e de produção de si e do mundo. Não que seja desejável ou necessário eliminar os artefatos da representação política que hoje prevalecem em nossas sociedades. Indicamos apenas que eles jamais expressarão o plano político da existência humana se não forem um momento acessório nas formas de participação. Enquanto nossas instituições e as relações que as organizam e perpetuam permanecerem assentadas na objetivação dessa dimensão política inerente à vida humana, não poderemos vislumbrar a concretização de um sistema de saúde fundado sobre valores democráticos.

Por este motivo, propomos a discussão da participação política desde o contexto cotidiano da gestão em saúde, salientando a necessidade de transpor para as relações institucionais a democracia participativa. Em nossa compreensão, este desafio remete antes a uma crise do sentido político de nossas práticas do que a um movimento imediato de desenho normativo de novos mecanismos de participação. Inclusive porque a questão maior nos parece ser como engendrar esses mecanismos de modo que sejam artifícios produtivos e constituintes de realidade social. Problema que exige o esforço de pensar as alternativas que abrem novas relações entre o exercício político (portanto normativo) de produção de valor e as práticas institucionais da gestão.

\section{Soberania e produção de valor: desafios colocados à gestão democrática em saúde}

Ao debater a relação entre soberania e produção de valor, nossa intenção é questionar o modo como nossas sociedades se organizaram na modernidade a partir da separação entre os planos econômico, político, subjetivo e social da existência humana. Interessa-nos particularmente problematizar a dicotomia sempre evocada entre Estado e sociedade civil, em razão da qual a instância estatal é apreendida como exterioridade, com base em uma premissa política que pretendemos contrapor: a da necessária divisão entre governados e governantes, entre governo (entendido como referência à política institucional) e vida social. Separação política que conforma o aparato estatal na modernidade a partir de práticas de centralização do governo, na medida em que o Estado institui-se como instância transcendente, que se posiciona como exterior às relações sociais, que se convertem em objeto de seu exercício normalizador e homogeneizador. 
Concordamos com a avaliação (Negri, 2001; 2002; 2003) de que a modificação da relação soberana ocorre não simplesmente como expansão do exercício do biopoder 4 edificado sobre o estado de exceção, mas como uma resposta às lutas que se articulam em função das formas modernas de dominação. Conforme esta leitura, a falência do Estado-nação, nos termos em que historicamente se edificou, expressa a dimensão constituinte das diversas estratégias de antipoder que se lhe contrapuseram, revelando, abertamente, que qualquer conceito substancial de soberania é por definição inadequado, já que “(...) a soberania não é uma substância autônoma, mas uma relação entre soberano e súdito. O poder soberano nunca é absoluto" (Negri, 2003, p. 73).

Pensar a crise do Estado-nação segundo esse prisma conduz à definição dada por Negri (2003) para o conceito de soberania como ponto de coincidência entre o econômico e o político. Nossa perspectiva de análise é remeter a interseção presente nessa designação do conceito de soberania à produção de valor; ou seja, tomar o processo de valoração como o alvo e o alimento da relação soberana, o que a torna o ponto de coincidência entre o econômico e o político. Isto representa analisar essa relação (esclarecido o fato de que não se pode efetivá-la em termos absolutos) como luta pela apropriação de significações, formas de engendramento e codificação da vida, da prática política e da produção. Luta pelos espaços de governo da vida, pela gestão de seus processos e do campo de possíveis que a interpela. Forma de abordagem que parte da compreensão de que a produção de valor possui uma prerrogativa de importância fundamental na constituição dos territórios existenciais que demarcam a experiência humana, corroborando a afirmação de Negri (2003) de que a decisão política é sempre produção de subjetividade.

Cabe, neste ponto, um esclarecimento. A não definição ou especificação do termo valor neste texto não é aleatória. Nosso propósito é justamente salientar a indiferenciação entre valor econômico, ético, jurídico e subjetivo. A intenção de forçar a dissolução dessas fronteiras de significação decorre justamente do entendimento de que o processo de valoração deve deixar de ser reportado unicamente ao âmbito econômico, sem o que a produção permanece confinada à relação de capital, e a política, ao âmbito do Estado. Tal leitura enraíza-se na compreensão de que é a ação constituinte do viver que produz valor, e que não pode ser delimitada pelos adjetivos modernos que pretenderam (como o afirma Santos (2006), ao dizer que a disputa política é também epistemológica) esquadrinhar a compreensão desses fenômenos em campos científicos como o social, o econômico e o político. Separações artificiais enredadas num jogo de poder que tem como finalidade a construção da ilusão de que o processo de valoração é resultado unicamente da inversão de capital. Não há produção que possa ser 
econômica sem ser subjetiva e política. E não é aleatório que a transformação da relação de soberania tenha tido relevantes sinalizações na produção e na organização do trabalho, a ponto de podermos falar numa sobreposição das relações de soberania e capital, que atualmente se espraiam por todo o campo de forças sociais como um processo extensivo de capitalização do social que desconhece as fronteiras tanto 'fabris' quanto nacionais (Negri, 2001; 2003). Essa extensão, em que se tangenciam globalização e reestruturação produtiva (a interface entre os dispositivos de soberania e de produção), traz à cena, sobretudo, o caráter parasitário do capital, sua dependência dos processos constituintes imanentes à vida.

A principal característica de tais transformações encontra-se no fato de que o trabalho passa a requisitar cada vez mais dimensões imateriais que não podem ser submetidas à temporalidade e à organização espacial dos instrumentos produtivos característicos da modernidade. As atividades intelectuais, comunicativas e afetivas dos sujeitos, em suma, a dimensão ontológica do trabalho, que torna vida e atividade produtiva "uma única realidade de efeitos" (Negri, 2003, p. 224), impõem-se como centrais à produção do valor, de modo que a quantificação do trabalho pelos parâmetros modernos (que utilizam o tempo como medida de intensidade e, portanto, de valoração) revela-se inadequada. A fronteira entre subjetividade, ou seja, os processos de constituição dos sujeitos, a ontologia social, e a produção de mercadorias e do mundo não se redesenham hoje ao modo das demarcações modernas. Como coloca Negri (2003, p. 243), “(...) a ontologia social torna-se biopolítica. Isso significa que a própria vida é investida pelo processo produtivo, o conjunto das paixões, das linguagens e dos afetos que constituem as subjetividades." Um dos aspectos principais neste processo é o fato de que a relação soberana passa a depender claramente da atribuição de valor que se efetiva fora dela. O que converte em problema político fundamental a disputa pela normalização dessa capacidade de designação e legitimação característica do processo de valoração, em sua dimensão de coletivização e produção do comum.

A relação entre vida e soberania nos aponta o fato de que, não obstante toda a configuração dos dispositivos de biopoder, a vida reafirma a dimensão ontológica que lhe é exclusiva, recoloca-se incessantemente como produção de subjetividades, de processos de singularização que instituem diferenças e rotas de fuga em face dos artifícios de normalização transcendente que se lhe impõem por todo o tecido social. Tal dimensão ontológica exerce-se como recusa às codificações preestabelecidas, a todos os modos de manipulação e de comando que procuram centralizar e expropriar ao máximo a autonomia dos movimentos de renormalização, em sua propriedade de construir novos modos de sensibilidade, de relação com o outro e de produção dos artifícios humanos (Guattari e Rolnik, 1999). 
Nesse sentido, as reorganizações do trabalho contemporâneo, fruto da irreversibilidade das lutas que se colocaram em distintos planos na modernidade, expõem toda artificialidade de um modo de produção erigido sobre a fissura entre concepção e execução, governantes e governados, cuja principal premissa é a objetivação dos sujeitos como mais um elemento produtivo. Em outras palavras, afirmam (na medida em que a valoração passa a depender em alto grau das atividades imateriais) um coeficiente significativo de liberdade ainda não codificado e reapropriado pelo capital.

Ao analisar a relação entre soberania e produção de valor, coloca-se o problema de como aproximar esse debate do tema da participação política no cotidiano institucional da gestão em saúde. O ponto de partida dessa reflexão deve necessariamente reportar-se aos valores que fundamentam o SUS como política pública, campo de lutas por direitos sociais que mobilizou amplos setores da sociedade brasileira em torno de um projeto setorial comum (o que não significa homogeneidade e consenso), que logrou institucionalizar em seu arcabouço jurídico o compromisso de transformação e justiça social que reuniu tão diferentes atores e segmentos da população engajados na reforma sanitária. Em sua implementação no período posterior à Constituição de 1988, o SUS concretizou-se como contexto de lutas sempre atualizadas, potentes na medida em que remetidas à defesa do direito à saúde como valor e bem comum, razão pela qual nos parece representar um movimento de proporções e efeitos singulares na história do Estado brasileiro. Intencionalidade política que exige a construção de novas formas de governo que estabeleçam rupturas substantivas com a tradição moderna de intervenção do 'estado de direito'.

É neste ponto justamente que cabe interrogar como a gestão dos serviços e sistemas de saúde tem respondido ao desafio de radicalização do projeto democrático do SUS, sem o qual a luta pela atenção à saúde, em outras palavras, a luta pela materialização dos princípios que o organizam formalmente, assume o caráter restrito de acesso e consumo de serviços. Uma breve retrospectiva de seu processo de consolidação nos mostraria o grande avanço que marcou sua institucionalização, em especial os instrumentos normativos de organização da atenção. Destaque-se, a esse respeito, o impacto das normas operacionais, da recente perspectiva de ampliação da pactuação federativa das políticas e a reorganização da Atenção Primária com a Estratégia de Saúde da Família. Esses são importantes exemplos de artifícios institucionais que responderam pela estruturação do SUS em âmbito nacional, por sua significativa capilaridade em tão abrangente contexto e num período histórico relativamente curto.

Nossa intenção é destacar que a presença marcante de artifícios normativos aponta qual tem sido a tendência hegemônica na gestão das políticas 
de saúde. Em razão dela, e não negligenciando os avanços alcançados em sua implementação, alguns indícios nos fazem questionar se os desenhos institucionais que hoje configuram o SUS respondem plenamente aos desafios de democratização das políticas do setor. Enormes são os obstáculos confrontados no cotidiano dos serviços, motivo pelo qual consideramos que a discussão sobre a gestão do SUS deve ser situada no cotidiano institucional, nos cenários concretos onde se efetiva. Castanheira (2000) nos ilustra algumas dessas dificuldades, entre elas

(...) os conflitos entre a necessidade institucional de estabelecer normas para o atendimento, e as necessidades mais imediatas trazidas pelos usuários; ou ainda, o conflito entre os interesses de grupos de trabalhadores da unidade, e de cada trabalhador individual, com as normas da instituição, de um lado, e com as demandas dos usuários, de outro (Castanheira, 2000, p. 222).

Um esclarecimento prévio faz-se necessário, ao propormos remeter a discussão da participação política à gestão do cotidiano institucional. Tratase do fato de que não retomamos em nossa análise a distinção entre gestão e gerência, 5 instituída pela Norma Operacional Básica do SUS/1996, a NOB-SUS/96. Concordamos com Ferla, Ceccim e Pelegrini (2003, p. 62) que, dada a persistência de orientações centralizadoras e frente ao desafio que se impõe à gestão em “(...) propor e fomentar arranjos descentralizados, resolutivos, solidários e permeáveis à participação da população, desde o sistema local de saúde", tal diferenciação torna-se secundária, uma vez que assumimos que

(...) o principal núcleo dos desafios colocados à gestão, nesse contexto, é relativo à capacidade de implementar práticas cotidianas suficientemente densas para produzir, no limite da radicalidade possível em cada situação, tensões e rupturas com a cultura instituída e com as tecnologias de gestão existentes (Ferla, Ceccim e Pelegrini, 2003, p. 65).

A tendência à centralização normativa que têm caracterizado a implementação do SUS, muitas vezes, mesmo (ou principalmente) por grupos comprometidos com o ideário do movimento sanitário, pode ser justificada como tentativa de garantir sua efetuação, num cenário histórico marcado por uma assistência pública à saúde fortemente mercantilizada, defendida por grupos de interesses vinculados ao complexo médico-industrial que acumulam grande poder de intervenção. Em face deste quadro, como o estudo das matrizes conceituais nos permitiu constatar, a luta por um sistema público de saúde universal e equânime foi identificada com o referencial da epidemiologia e com as correntes que tinham por objeto o planejamento e 
planificação das políticas públicas, influenciadas pela produção teórica da Comissão Econômica para a América Latina e o Caribe (Cepal).

Ainda que muitas vezes advogando a participação popular e o planejamento ascendente, os modelos de gestão propostos no âmbito do planejamento e da programação em saúde redundaram na permanência de práticas calcadas na centralização normativa da gestão das políticas públicas e no controle do processo de trabalho nas instituições de saúde. Essas formulações expressam uma concepção de política marcada pela noção de antagonismo, em que a alteridade é percebida como fato inevitável, porém refém de um jogo de contraposições em que os projetos políticos disputam por prevalecer. A política seria, assim, terreno da aniquilação do outro, campo de disputa e construção de hegemonia, que, mesmo quando defendida desde a perspectiva do contrapoder, não deixa de implicar um horizonte de totalização e de superação da alteridade, vivida como oposição frontal. O planejamento estratégico situacional, 6 maior referência do campo, possibilita visualizar com clareza essa concepção de política.

A normalização e a racionalização das práticas foi, em decorrência dessa trajetória, fortemente identificada com o projeto de reforma sanitária, como caminho impreterível para a construção de um outro modelo assistencial, delineando como conseqüência os modos de gestão das políticas de saúde. Características que convergem com a tradição que tem orientado os modos de gestão modernos, cuja emergência histórica é marcada por necessidades específicas do modo de produção que se configura a partir do final do século XIX, com o desenvolvimento do capital monopolista.

Nesse contexto, a emergência da gerência sinaliza, principalmente, a redução da autonomia dos trabalhadores sobre a tarefa, condição legitimada pela separação nas organizações sociais entre o momento da concepção e o da execução. Concordamos com a análise feita por Campos (2000b), segundo a qual, não obstante seus compromissos democráticos, a efetivação do SUS seguiu os cânones dessa racionalidade gerencial hegemônica, marcada pelo exercício do controle e da disciplina.

Os baluartes desse modelo de gestão são os mecanismos de indução financeira responsáveis pela implementação dos programas verticais e das normas operacionais que estruturaram o sistema. Forma de condução que transparece a premissa de uma grande concentração de poder no 'núcleo central' da gestão e a respectiva limitação da autonomia dos demais segmentos e sujeitos implicados. Não seria, afinal, coincidência que grande parte dos problemas identificados (como os relacionados anteriormente) no cotidiano do sistema diga respeito à relação dos sujeitos com as normas que organizam a produção dos serviços no SUS. A tentativa de exercer um controle eficaz apenas é viável se acompanhada de formas de contenção, ou mesmo de eliminação, das subjetividades e suas singularidades. Em certa 
medida, podemos imaginá-las como instrumentos de garantia do sistema, apesar dos sujeitos que o compõem.

Conforme vimos, essa tendência em parte se explica pela preocupação de transformação do modelo assistencial a partir da integração das práticas clínicas e sanitárias. Mesmo com a legitimidade histórica desse objetivo, não há como desconsiderar que é impossível, ou melhor, que não devemos sequer esperar ou intencionar excluir do plano das intervenções e da produção de saúde as singularidades e os movimentos desejantes que constituem o social. Ao contrário, em nossa avaliação a discussão dos modos de gestão em saúde remete à impossibilidade de total centralização do processo decisório.

Mesmo sendo o SUS organizado de forma centralizada por normas, protocolos e programas, todos esses sujeitos, com suas diferentes inserções, são um pouco autores desse desenho institucional e de seus fluxos singulares em cada contexto, pois não se pode subsumir o fato de que normas e instrumentos operacionais somente existem como prática social em situação, compreendida aqui segundo a acepção que lhe confere Matus (1989). Aspecto que coloca um grande desafio aos modos de gestão, já que tal vitalidade depende da percepção de que sua intervenção diz antes da construção de relações, das tecnologias leves, segundo Merhy (2005), da configuração de redes cooperativas, do que da estrita normalização do processo de trabalho. Mesmo porque a ação, atividade por definição normativa dos sujeitos, e nessa medida sua participação política, não pode ser de forma alguma isolada das dimensões reticulares em que se tecem as relações humanas, o que faz com que seus efeitos tenham como movimento primordial a tendência a espraiar-se sem que seja possível sua objetivação ou a previsão inconteste de seus efeitos. A antecipação das consequências da ação revela-se impossível, já que seus efeitos são imanentes e se articulam assim com os demais processos que compõem a realidade como artefato humano compartilhado.

Em consequência, voltando para a questão da gestão em saúde, podemos afirmar que a coordenação dos processos de trabalho e da organização do sistema não deve ter como pressuposto a centralização do poder de decisão. Afinal, são nas decisões do cotidiano que a assistência ganha forma e é no contexto dessas decisões que os sujeitos implicados podem exercer sua capacidade normativa, podem exercer a participação no SUS como uma atividade política. É preciso, sobretudo, que os atores e segmentos sociais, historicamente excluídos dos processos de decisão da gestão das políticas públicas, reconheçam esses territórios institucionais enquanto espaços nos quais seu saber e sua experiência são requisitados como estratégia política de constituição de realidades sociais. Sem o que os serviços de saúde tendem a expressar o movimento de permanência nos registros que organizam as normas das instituições dentro dos limites modernos que as caracterizam. 
Frente a esses desafios, endossamos a avaliação de Campos (2000b, p. 41) sobre o problema do "fortalecimento dos sujeitos (em sua capacidade de análise e intervenção) e a construção de democracia institucional". Imaginamos que essa é uma perspectiva interessante na medida em que remete a democracia à capacidade de ser normativo, o que implica, necessariamente, as possibilidades de cogestão dos processos institucionais. A participação no SUS poderia ser então pensada como o problema de construção dessa democracia institucional e de publicização dos processos decisórios que conformam as políticas de saúde. Para o que é preciso desarticular os discursos que pretendem justificar como questão técnica a centralização do poder de governo, o que nos leva a questionar as decisões e opções técnicopolíticas que fundamentam os desenhos institucionais do SUS.

Não pretendemos sugerir a possibilidade de sociedades sem mecanismos de regulação, mas apontar que é preciso incorporar em nossas instituições o movimento normativo da atividade em seu plano de imanência. Isto significa não a existência de normas a serem seguidas de forma estrita, mas o reconhecimento no âmbito dos espaços institucionais do agir como produção normativa. Significa criar artifícios e dispositivos que promovam planos de visibilidade que nos permitam constatar os efeitos da atividade e de suas sinergias, o modo como potencializam ou constrangem outras esferas de ação, bem como as implicações de seus vetores de determinação. Em outras palavras, planos de visibilidade que exponham esse exercício normativo em sua capacidade de produzir repercussões e efeitos de realidade, e em sua condição de atravessamento e ponto de emergência singular de outros movimentos de normalização. O que também poderia ser lido como esforço de "publicizar os autogovernos", "o exercício privado do agir", como propõe Merhy (2005). Por este motivo, defendemos a necessidade de constituição de planos de visibilidade para os valores que permeiam e embasam os processos decisórios que determinam o sistema de saúde, porque é no âmbito da gestão desses processos, nos territórios reais onde ocorrem, que podemos pensar a participação política. A participação como sendo ela própria uma atividade de luta e saúde.

A dimensão política dessa experiência concerne, assim, ao plano de visibilidade a partir do qual podemos publicizar as implicações normativas da atividade em sua produção de sentidos e efeitos de real. Nessa apreensão, a gestão é feita por todos, é responsabilidade ética de todos, já que mesmo sob os maiores cerceamentos, a atividade do humano produz realidade e determina nossos territórios existenciais. O que significa pensar a realidade (institucional) necessariamente como coprodução. Para pensar esse desafio quanto à produção de valor-saúde (como bem comum), julgamos necessário retomar a inovação que o conceito de cogestão trabalhado por Campos 
(2000b) nos oferece, salientando um elemento de divergência importante. Embora tenhamos uma avaliação convergente sobre a necessidade de democratização institucional, a forma como o autor articula a cogestão nos parece reduzir sua amplitude ao limite das equipes de trabalho, ou, em sua terminologia, às unidades de produção. Circunscrição que ao nosso ver não consegue romper, de fato, com o modo operante do funcionamento institucional, em suas inércias, clausuras e em seu peso gravitacional, que procura sempre conter e fixar a intensidade dos fluxos sociais, asfixiá-los com sobrecodificações e hierarquias. Aspectos que o próprio autor aborda, ao falar da tendência de fechamento que as unidades de produção revelam, o que justificaria segundo ele a função de apoio e liderança.

Em nossa perspectiva, discutir a cogestão no âmbito das instituições de saúde representa uma passagem do entendimento da gestão como organização da operação de tarefas e suas distribuições no trabalho da equipe para o plano da articulação em rede das atividades de produção de saúde. O que significa necessariamente extrapolar os limites das equipes e unidades em direção às conexões possíveis com o território produtivo em que se situam. Seria esse um novo sentido para o conceito de territorialização do sistema de saúde trabalho pelo enfoque teórico dos distritos sanitários. Aproximação que resgata alguns de seus objetivos, que consideramos atuais, como por exemplo a necessidade de criar maior plasticidade nos mecanismos da gestão e de efetuar uma transição de normas duras para normas brandas.

No entanto, apesar dessas convergências, o conceito de territorialização apresenta aqui uma apreensão diversa da proposta do distrito sanitário, pois não se trata de conhecer o território para melhor intervir, para melhor responder às suas necessidades de saúde (o que mantém as fronteiras funcionais da instituição). Ao contrário, a territorialização significa aqui a socialização da instituição no território produtivo, no sentido de democratizar o poder normativo que caracteriza sua intervenção ao limite da transformação das instituições em malhas articuladoras das redes deste território, em sua potencialidade de produção de saúde. Significa investir no território diretamente como campo da produção de saúde, concretizando novas articulações institucionais que não atualizem a intervenção em saúde como uma reprodução de normalizações sobrecodificadas e heterodeterminadas. Remete, portanto, a uma compreensão da coprodução como socialização e democratização da constituição de artifícios institucionais, com base na potência produtiva do trabalho imaterial, em sua dependência direta dos fluxos e redes sociais que promovem a socialização dos saberes, dos dispositivos tecnológicos e organizativos. Pensar a coprodução de saúde em suas articulações com o território demanda, portanto, inovações ('sinergias produtivas', não antecipáveis, não passíveis 
de prescrição) que produzem, sobretudo, novas formas de ver e sentir, novos territórios existenciais.

A cogestão das instituições seria, então, a outra face da coprodução de saúde. Vinculação que explicitamos por realocar a descentralização do sistema de saúde no horizonte da efetiva apropriação democrática dos processos de sua gestão. Transformações administrativas dos serviços de saúde que supomos depender da exposição dos espaços institucionais à multiplicidade normativa dos fluxos societários e de suas composições singulares. Uma forma de ruptura da tendência de centralização e concentração do poder normativo da gestão que tem ocasionado ao SUS um vasto leque de dificuldades em articular desenhos institucionais adequados às especificidades locorregionais. Ou melhor, que tem apresentado constrangimentos para concretização do SUS como território público, plano de visibilidade que torna acessível aos seus sujeitos a dimensão política das práticas de saúde, ao mesmo passo em que se efetua como contexto de expressão e materialização de sua diversidade e singularidades na produção de saúde .

A cogestão seria, assim, um dispositivo de redistribuição do poder nas relações sociais (objetivo do planejamento conforme Testa (1989), afirmando definitivamente a participação política como relativa às implicações decisórias da atividade (implicações normativas, portanto). Participação política como poder de intervir na capacidade institucional de regular a temporalidade e a intensidade constituinte da dinâmica societária. Ou seja, cogestão como ampliação das possibilidades de avaliação dos territórios existenciais agenciados pelas práticas de saúde, na perspectiva em que discutimos anteriormente produção do valor e atividade normativa. Nesse sentido, dispositivo democrático, que transformaria os espaços institucionais não mais em lócus de aprisionamento do virtual, mas em rede cooperativa em que ocorre a modulação ética das forças que o constituem (já que a vida social nos solicita permanências e territórios institucionais).

\section{Considerações provisórias sobre a gestão das políticas públicas de saúde e suas perspectivas pós-soberanas}

Quando situamos a participação como modo de gestão das políticas públicas, propomos não uma inscrição do social no político, mas a dissolução das fronteiras modernas que codificam a existência humana e pretendem separar esses dois planos. Em outras palavras, defendemos que fortalecer a dimensão política da participação no SUS significa desconstruir todo um repertório de polarizações - como público x privado, Estado x sociedade civil, participação política x participação social - que se atualizam em suas 
práticas e configurações institucionais. Quando definimos a política como experimentação, invenção de territórios existenciais, criação de valor inerente às implicações normativas da atividade, nossa perspectiva é justamente desfazer tais demarcações.

A dimensão política diz respeito, em nossa leitura, às condições de produção e apropriação de sentidos que decorrem diretamente da relação entre igualdade e diferença. Igualdade entendida como direito comum à diferenciação, e diferença entendida como invenção (de si e do mundo), constituição ética do tempo (Cocco, 2001). Ou seja, falamos da realidade como invenção política, que, sendo colaboração, cooperação, co-produção, implica necessariamente o exercício normativo de criação de valor. Na medida em que a igualdade que o direito assegura e legitima agencia a potência de diferir, podemos remeter a política definitivamente à liberdade, à liberdade de inventar o novo, de concretizar o milagre que nos anuncia Arendt (1981). Liberdade supõe, portanto, o acesso de todos aos bens comuns que tornam possível a criação, que instituem o plano de determinação dos problemas com que interrogamos a realidade, e que nos permitem formular novas questões e produzir outras respostas, tornando aberto o tempo da existência, que não pode ser contido em nenhuma configuração particular do possível, por mais oportuna que seja. Liberdade e justiça se encontram quando a política é materializada como recusa (produtiva, é preciso enfatizar) em restringir em nossas instituições a potência de constituição que tem a multiplicidade humana. Recusa política em estabelecer quem tem o direito de inventar e a quem cabe reproduzir o que há, recolhendo-se aos contornos e ditames do existente.

Propomos, assim, pensar a política fora dos termos que a aprisionam na contradição, na disputa por hegemonia e superação do outro, tão característica dos enfrentamentos modernos, em suas maneiras de estabelecer a oposição dentro de alternativas já conhecidas. Não falamos, portanto, da política como clivagem que reduz o real ao jogo dialético das polarizações e dicotomias. Pensar a política como invenção, experimentação, significa assumir que a alteridade é condição tanto da diferenciação que nos constitui e nos permite qualquer individuação como da coprodução de realidade. Assim, podemos dizer que “(...) as individualidades e as coletividades não são mais o ponto de partida, mas o ponto de chegada de um processo aberto, imprevisível, arriscado, que deve ao mesmo tempo criar e inventar estas mesmas individualidades e coletividades" (Lazzarato, 2006, p. 28). O que significa dizer que tais individualidades e coletividades não são os sujeitos (demiurgos) da política (cujo objetivo seria, nos termos da modernidade, prevalecer uns sobre os outros), mas o efeito político do encontro, da coprodução, da coadaptação. O conceito de Política que adotamos se define não 
em termos de igualdade (formal) que se contrapõe às diferenças (sociais), mas como coprodução de realidade que se concretiza nas relações entre igualdade e diferença, como acesso e uso dos bens comuns, em sua capacidade indeterminada e aberta de criação de valor.

O desafio que se nos apresenta é por definição político, pois nos convoca à invenção de direitos que operem paradoxalmente como devir e permanência, como garantia de condições materiais de igualdade que apenas adquirem sentido se transformadas em expressão constituinte, procedimento absoluto da liberdade (Lazzarato, 2006; Negri, 2002). Desafio que Lazzarato, utilizando a menção de Franco Berardi à constitucionalização do devir, enuncia como sendo relativo à invenção de "(...) um conjunto de regras, de dispositivos, de instituições previstas para ir se transformando à medida que se modifica o conteúdo de sua aplicação, à medida que novos possíveis se criem e se atualizem" (Lazzarato, 2006, p. 243). Perspectiva que explicita as implicações que desejamos incorporar ao conceito de gestão participativa, como possível 'tecnologia de governo' pós-soberana. A participação na política de saúde converte-se, deste modo, no problema de constituição de uma política pública pós-soberana7, que consiga permanecer aberta e imprevisível, resguardando, contudo, condições materiais de igualdade. Nesse sentido, uma forma de produzir políticas públicas que rompa com os mecanismos da soberania moderna ao incorporar em seus desenhos institucionais a imprevisibilidade da produção normativa, forjando-se como dispositivo ético (portanto, aberto e comum) de produção de valor.

Ao provocarmos o debate sobre as perspectivas da participação política no SUS desde a perspectiva da pós-soberania, propomo-nos questionar a relação entre norma e realidade, o fato de que toda intervenção estatal tornase um procedimento de exceção quando nega as implicações normativas da atividade humana e busca inserir em um regime de determinação transcendente (ainda que ele seja falho por definição) o modo como a vida produz realidade. Pensar a dinâmica entre o real e as políticas públicas com o quadro de referência característico da modernidade nos fez prisioneiros de uma relação fechada de vínculos de causalidade, sempre buscando promover em arranjos sequenciais certos resultados específicos, já definidos. Todas as dissonâncias da aplicação do modelo são vistas como desvios a serem contornados e forçosamente recolocados na estrada que conduz à norma-meta estabelecida. Lógica de intervenção pautada pela afirmação da necessidade de fechamento do tempo numa síntese, de condução do processo ao seu fim.

Nossa posição é a de que tal dinâmica entre o real e as políticas públicas deve incorporar em seus desenhos institucionais a imprevisibilidade da produção normativa. O que nos solicita ensaiar artifícios institucionais que 
expressem o movimento do real em sua complexidade, na abertura processual de seus fluxos. Um primeiro passo nessa direção seria justamente a percepção da distinção entre real e realidade, entre a potencialidade virtual que os processos mobilizam em seu devir e a atualização que conseguimos reconhecer como efeito tangível deles. Distinção que nos remete à existência, mesmo quando não efetuada, de malhas de força, tramas do possível não enunciado, que não podem ser fotografadas em nossas lentes de observação e entendimento habituais, e cuja existência apenas advém na imanência dos agenciamentos que as convocam. Todo efeito de realidade só se concretiza com a afluência de inúmeros processos e fluxos, discretos ou mesmo não perceptíveis, cujos deslocamentos, atravessamentos, imbricações e tensionamentos constituem uma paisagem de realidade movente, em perene transformação.

Não se deve supor que essa leitura redunde em esvaziar das políticas públicas de saúde os compromissos éticos que as justificam. Ao questionarmos a racionalidade instrumental que fundamenta a concepção moderna de intervenção das políticas públicas, não pretendemos subtrair as implicações ético-políticas das intervenções em saúde. Ao contrário, consideramos como questão fundamental a produção de visibilidade para as intencionalidades e direcionalidades que norteiam as intervenções feitas. O que ressaltamos, por outro lado, é a impossibilidade e os riscos inerentes às tentativas de estabelecer o percurso segundo a racionalidade instrumental que usualmente se presentifica nos programas e modelos normatizados.

Nesse sentido, defendemos que o compromisso ético que subjaz às políticas de saúde não deve ser entendido como a garantia de determinados desenhos normativos fechados e focados em objetivos preestabelecidos. O exercício ético na gestão das políticas públicas de saúde supõe, em contrapartida, recusar a reificação da realidade, a heteronomia da atividade, as hierarquias e exclusões institucionalizadas, em favor de agenciamentos outros, cujas intencionalidades e efeitos se legitimem em seu próprio movimento de efetuação, expandindo seu campo de influência em razão da adesão que sua coerência e consistência mobilizam no tecido social. Postulado da coerência, em referência ao conceito de Testa (1995), que remete aqui particularmente ao modo como a política pública responde por seus efeitos, sem intentar prescrevê-los e sem organizar sua concretização desde qualquer forma de centralização e expropriação normativa.

Desta maneira, as políticas públicas de saúde são pensadas como artifícios de intervenção institucional e publicização das implicações normativas que resultam na transformação ou atualização dos territórios existenciais. Substituição da ação política teleológica e representativa que toma, desde uma pretensa exterioridade, o mundo e os processos sociais como objeto, 
por políticas públicas que expressam a compreensão de que as transformações sociais desejadas são da ordem da conseqüência, da coerência e consistência dos processos que engendram, e não de projetos previamente definidos. Políticas que construam a democracia como experiência do viver, segundo Freire (2005), e que por isto requisita estratégias ampliadas de participação, que conformem talvez um modo pós-soberano de produção da política de saúde. Pós-soberano porque autopoiético, em movimento constante de conformação de propósitos, intervenções, sentidos, enfim, de políticas públicas orientadas para a criação de valor como expressão do poder constituinte dos processos sociais.

O desafio que se coloca à constituição contemporânea das políticas públicas é, portanto, mais amplo do que a princípio se apresenta. Suas implicações éticas decorrem justamente da ficção que representa qualquer delimitação dos processos sociais em relações de inclusão e exclusão, qualquer ilusão que pretenda localizar a soberania em artefatos institucionais específicos. A transversalidade dessa implicação nos impõe o compromisso ético de tornar aparentes os efeitos engendrados pelos artifícios institucionais que criamos, de expô-los às apropriações e à avaliação comum, sem procurar forçar o real aos moldes de nossos modelos e expectativas. Compromisso ético, porque necessariamente atinente à produção do comum, ou melhor, ao desafio de libertá-lo dos limites ontológicos impostos na relação de soberania. Afinal, a radicalidade do sentido da política é a liberdade, liberdade de produção do novo.

\section{Notas}

1 Pesquisadora da Escola Politécnica de Saúde Joaquim Venâncio, da Fundação Oswaldo Cruz (EPSJV/Fiocruz), Rio de Janeiro, Brasil. Doutora em Saúde Coletiva pela Universidade do Estado do Rio de Janeiro (Uerj). < franciniguizardi@fiocruz.br> Correspondência: Fundação Oswaldo Cruz, Escola Politécnica de Saúde Joaquim Venâncio, Avenida Brasil, 4.365, Manguinhos, Rio de Janeiro, Brasil, CEP 21040-900.

2 Ver, em Referências, Wendhausen e Cardoso, 2007; Serapioni e Romani, 2006; Bello, 2006; Guizardi e Pinheiro, 2006; Moroni, 2005; Cohn, 2003; Guizardi, 2003; Ribeiro e Andrade; 2003; Soares e Ribeiro, 2003; Tatagiba, 2002; Labra e Figueiredo, 2002; Wendhausen e Caponi, 2002; Pessoto, Nascimento e Hiemann, 2000; Ribeiro, 1997; Pinheiro, 1995; Spozati e Lobo, 1992.

3 Adotamos o conceito de dispositivo em uma acepção foucaltiana, segundo a qual este conceito remete às redes que se delineiam entre elementos heterogêneos (leis, medidas administrativas e de segurança, enunciados científicos, componentes de discursos, insti- 
tuições etc.), conformando certa 'disposição' destes elementos que se revela por si mesma produtora de efeitos (Agamben, 2005).

$4 \mathrm{O}$ biopoder é referido no texto segundo uma perspectiva foucaultiana e corresponde ao modo pelo qual a vida é investida de um arsenal de dispositivos que visam a sua governamentalização, o controle e a organização das populações como tecnologia de governo sobre seus fenômenos de conjunto. Em sua dimensão de totalização da vida coletiva, o biopoder toma como objeto não o homem-corpo, mas o homem-ser vivo, ou, de modo mais explícito, o homem-espécie. Desse modo, as tecnologias biopolíticas dirigem-se especificamente à população, à aplicação de novos tipos de saber e aparelhos de poder que permitiram sua manipulação e uma intervenção direta em seus fenômenos de conjunto. Segundo Negri (2003), o biopoder é um conceito que trata da "economia política da vida em geral" (Negri, 2003, p. 105), da “(...) gestão da saúde, da higiene, da alimentação, da sexualidade, da natalidade na medida em que esses sujeitos se tornam, no desenvolvimento do Estado Moderno, coisas importantes para o poder" (Negri, 2003, p. 103).

5 Na Norma Operacional Básica do SUS de 1996, a gestão é definida como “a atividade e a responsabilidade de dirigir um sistema de saúde (municipal, estadual ou nacional), mediante o exercício de funções de coordenação, articulação, negociação, planejamento, acompanhamento, controle, avaliação e auditoria". A gerência, por sua vez, "é conceituada como sendo a administração de uma unidade ou órgão de saúde (ambulatório, hospital, instituto, fundação etc.) que se caracteriza como prestador de serviços ao sistema".

6 O planejamento estratégico situacional (PES) foi concebido por Carlos Matus, economista chileno, a partir de sua experiência como ministro da Economia do governo Allende, entre 1970 e 1973, e representa um contraponto e crítica das perspectivas de planificação normativa. O enfoque do PES surge no âmbito mais amplo do planejamento econômico-social, partindo do reconhecimento da complexidade, fragmentação e incerteza que caracterizam os processos sociais. Trata-se de uma metodologia de planejamento por problemas, que tem por objeto privilegiado problemas mal-estruturados e complexos. Nela, o planejamento é entendido como um cálculo que precede e preside a ação, para o qual três variáveis importam particularmente: o projeto de governo, a capacidade de governo e a governabilidade. A proposta metodológica do PES assenta-se em quatro momentos, compreendidos como um processo permanente e, em grande medida, simultâneo, que se repete necessariamente, mudando, contudo, o conteúdo, o contexto e a referência temporal que o situa, a saber: o momento explicativo, o normativo, o estratégico e o táticooperacional.

7 Termo utilizado por Giuseppe Cocco em discussão realizada em seminário de pesquisa na Escola de Serviço Social da Universidade Federal do Rio de Janeiro (UFRJ). 


\section{Referências}

AGAMBEN, Giorgio. Estado de exceção. São Paulo: Boitempo Editorial, 2004.

. O que é um dispositivo. Outra travessia: revista de literatura, n. 5. Ilha de Santa Catarina, p. 9-16, 2005.

ARENDT, Hanna. A condição humana. Rio de Janeiro: Forense Universitária; Rio de Janeiro: Salamandra; São Paulo: Edusp, 1981.

O que é a política. Rio de Janeiro: Bertrand Brasil, 1998.

BELLO, Carlos Alberto. Orçamento, redistribuição e participação popular no município de São Paulo. São Paulo em Perspectiva, v. 20, n. 3, São Paulo, p. 95-105, 2006.

BRASIL. Ministério da Saúde. Secretaria de Gestão Participativa. Participasus: Política Nacional de Gestão Participativa para o SUS. 2005. Disponível em: http://portal.saude.gov.br/portal/arquivos/ pdf/Participasus $\% 20 \% 20$ Politica $\% 20$ Nacio nal $\% 20$ de $\% 20$ GP $\% 20$ para $\% 200 \% 20$ SUS. pdf. Acesso em: 10 set. 2008.

CAMPOS, Gastão W.S. Considerações sobre o processo de administração e gerência de serviços de saúde. In: CAMPOS, Gastão W. S.; MERHY, Emerson E.; NUNES, Everardo D. Planejamento sem normas. São Paulo: Hucitec, 1989, p. 9-32.

Considerações sobre a arte e a ciência da mudança: revolução das coisas e reforma das pessoas. In: CECILIO, Luiz Carlos O. (Org.). Inventando a mudança na saúde. São Paulo: Hucitec, 1994. p. 29-88.

Saúde pública e saúde coletiva: campo e núcleo de saberes e práticas. Ciência \& Saúde Coletiva, v. 5, n. 2, Rio de Janeiro, p. 219-230, 2000a.

Um método para análise e cogestão de coletivos: a constituição do sujeito, a pro- dução de valor de uso e a democracia em instituições: o método da roda. 1. ed. São Paulo: Hucitec, 2000b. 236 p.

Saúde Paideia. 2. ed. São Paulo: Hucitec, 2005, 185 p. A saúde pública e a defesa da vida. 3. ed. São Paulo: Hucitec, 2006, 175 p.

Reflexões sobre o Sistema Único de Saúde: inovações e limites. Revista do Serviço Público, Brasília, p. 123-132, 2007. Volume especial.

CANGUILHEM, Georges. Meio e normas do homem no trabalho. Pro-Posições, Faculdade de Educação, Unicamp, v. 12, n. 2-3, p. 38-52, 2001.

CAPONI, Sandra. Georges Canguilhem y el estatuto epistemológico de salud. História, Ciências, Saúde, v. 4, n. 2, p. 287-307, 1997.

CASTANHEIRA, Elen Rose. A gerência na prática programática. In: SCHAIBER, Lilia B. (Org.) Programação em saúde hoje. São Paulo: Hucitec, 1990.

COCCO, Giuseppe Mario. Introdução. In: LAZZARATO, Maurizio; NEGRI, Antonio. Trabalho imaterial. Rio de Janeiro: DP\&A Editora, 2001. p. 7-24.

COHN, Amélia. Estado e sociedade e as reconfigurações do direito à saúde. Ciência \& Saúde Coletiva, v. 8, n. 1, Rio de Janeiro, p. 9-18, 2003.

FERLA, Alcindo A.; CECIM, Ricardo B.; PELEGRINI, M. L. M. de. Atendimento integral: a escuta da gestão estadual do SUS. In: PINHEIRO, Roseni; MATTOS, Ruben A. de (Orgs.). Construção da integralidade: cotidiano, saberes e práticas em saúde. Rio de Janeiro: IMS, Uerj: Abrasco, 2003, p. 61-88.

FOUCAULT, Michel. Microfisica do poder. Rio de Janeiro: Graal, 1988. 
Vigiar e punir: nascimento da prisão. 20. ed. Petrópolis: Vozes, 1999, 262 p.

FREIRE, Paulo. Educação como prática da liberdade. 28. ed. São Paulo: Paz e Terra, 2005.

GERSCHMAN, Silvia. A democracia inconclusa: um estudo da reforma sanitária brasileira. 1. ed. Rio de Janeiro: Editora Fiocruz, 1995. 189 p.

GUATTARI, Felix; ROLNIK, Sueli. Micropolitica: cartografias do desejo. Petrópolis: Vozes, 5. ed., 1999. 327 p.

GUIZARDI, Francini L.; PINHEIRO, Roseni (orientadora). Participação política e os caminhos da construção do direito à saúde: a experiência da pastoral da saúde nos municípios de Vitória e Vila Velha. Dissertação (Mestrado em Saúde Coletiva), IMS, Uerj, 2003.

. Participação política e cotidiano da gestão em saúde: um ensaio sobre a potencialidade formativa das relações institucionais. In: PINHEIRO, Roseni; MATTOS, Ruben (Orgs.). Gestão em redes: práticas de avaliação, formação e participação na saúde. Rio de Janeiro: Cepesc-IMS/Uerj-Abrasco, 2006, p. 369-384.

LABRA, Maria Eliana; FIGUEIREDO, Jorge A. Associativismo, participação e cultura cívica: o potencial dos conselhos de saúde. Ciência \& Saúde Coletiva, n. 3, p. 537-547, 2002.

LAZZARATO, Maurizio. As revoluções do capitalismo. Rio de Janeiro: Civilização Brasileira, 2006, 268 p.

MATUS, Carlos. Fundamentos da planificação situacional. In: RIVERA, Francisco J.U. (Org.). Planejamento e programação em saúde: um enfoque estratégico. São Paulo: Cortez, 1989, p. 107-149.

Adeus, senhor presidente: governantes governados. São Paulo: Fundap, 1997, $381 \mathrm{p}$.
MERHY, Emerson E. Em busca da qualidade dos serviços de saúde: os serviços de porta aberta para a saúde e o modelo tecnoassistencial em defesa da vida (ou como aproveitar os ruídos do cotidiano dos serviços de saúde e colegiadamente reorganizar o processo de trabalho na busca da qualidade das ações de saúde). In: CECILIO, Luiz Carlos C.O. (Org.). Inventando a mudança na saúde. São Paulo: Hucitec, 1994, p. 117-160.

Saúde: a cartografia do trabalho vivo. São Paulo: Hucitec, 2005, 189 p.

Em busca do tempo perdido: a micropolítica do trabalho vivo em saúde. In: MERHY, Emerson E.; ONOCKO, Rosana. (Orgs.). Agir em saúde: um desafio para o público. 3. ed. São Paulo: Hucitec, 2007, p. 71-112.

MERHY, Emerson E. et al. Em busca de ferramentas analisadoras das tecnologias em saúde: a informação e o dia-a-dia de um serviço, interrogando e gerindo trabalho em saúde. In: MERHY, Emerson E.; ONOCKO, Rosana. (Orgs.). Agir em saúde: um desafio para o público. 3. ed. São Paulo: Hucitec, 2007, p. 113-160.

MORONI, José Antônio. O direito à participação no Governo Lula. Saúde em Debate, Rio de Janeiro, v. 29, n. 71, p. 284-304, set.dez. 2005.

NEGRI, Antonio; HARDT, Michael. Império. Rio de Janeiro-São Paulo: Record, 2. ed., 2001, $501 \mathrm{p}$.

NEGRI, Antonio. O poder constituinte: ensaios sobre as alternativas da modernidade. Rio de Janeiro: DP\&A Editora, 2002, 480 p.

Cinco lições sobre império. Rio de Janeiro: DP\&A Editora, 2003, 280 p.

PESSOTO, Umberto C.; NASCIMENTO, Paulo R.; HIEMANN, Luiza S. A gestão semiplena e a participação popular na administração da saúde. Cadernos de Saúde 
Pública, v. 17, n. 1, Rio de Janeiro, p. 89-97, 2001.

PINHEIRO, Roseni. Conselhos de saúde: o direito e o avesso. Dissertação (Mestrado em Saúde Coletiva). IMS/ Uerj, 1995.

RIBEIRO, José M. Conselhos de saúde, comissões intergestores e grupos de interesse no Sistema Único de Saúde (SUS). Cadernos de Saúde Pública, v. 13, n. 1, Rio de Janeiro, p. 81-92, 1997.

RIBEIRO, Ednaldo A.; ANDRADE, Cleverson M. Cultura política e participação diferenciada: o caso do conselho municipal de saúde do município de Dois Vizinhos, estado do Paraná. Acta Scientiarum. Human and Social Sciences. Maringá, v. 25 n. 2, p. 349-358, 2003.

SANTOS, Boaventura V. S. Renovar la teoría crítica y reinventar la emancipacion social: encuentros em Buenos Aires. Buenos Aires: Consejo Latinoamericano de Ciencias Sociales - Clacso, 1. ed., 2006. 110 p.

SCHWARTZ, Yves. Trabalho e ergologia. In: SCHWARTZ, Yves; DURRIVE, Louis. (Org.). Trabalho e ergologia: conversas sobre a atividade humana. Niterói: EdUFF, 2007, p. 25-36.

SCHIERA, P. Estado moderno. In: BOBBIO, Noberto; MATTEUCCI, Nicola; PASQUINO, Gianfranco. Dicionário de política. 4. ed. Brasília: Editora UnB, 1993, p. 425-431.

SERAPIONI, Mario; ROMANI, Oriol. Potencialidades e desafios da participação em instâncias colegiadas dos sistemas de saúde: os casos de Itália, Inglaterra e Brasil. Cadernos de Saúde Pública, v. 22, n. 11, Rio de Janeiro, p. 2411-2421, 2006.

SPOZATI, Aldaíza; LOBO, Elza. Controle social e políticas de saúde. Cadernos de Saúde Pública, v. 8, n. 4, Rio de Janeiro, p. 366$378,1992$.

TATAGIBA, Luciana. Os conselhos gestores e a democratização das políticas públicas no
Brasil, em DAGNINO, E. (org.) Sociedade civil e espaços públicos no Brasil, São Paulo: Paz e Terra, 2002, p. 47-104.

TELLES, Vera. S. Sociedade civil e a construção de espaços públicos. In: DAGNINO, Evelina (Org.). Os anos 90: saúde e sociedade no Brasil. São Paulo: Brasiliense, 1994, p. 91-102.

TESTA, Mario. Planejamento em saúde: as determinações sociais. In: NUNES, Everardo D. As ciências sociais em saúde na América Latina: tendências e perspectivas, s.l. Organizacion Panamericana de la Salud, 1985, p. 335-367.

Pensamento estratégico e lógica de programação: o caso da saúde. São Paulo-Rio de Janeiro: Hucitec-Abrasco, 1995, 306 p.

Mario Testa e o pensamento estratégico em saúde. In: RIVERA, Francisco J.U. (Org.). Planejamento e programação em saúde: um enfoque estratégico. São Paulo: Cortez, 1989, p. 59-104.

VASQUES, Maria Luisa et al. Participação social nos serviços de saúde: concepções dos usuários e líderes comunitários em dois municípios do Nordeste do Brasil. Cadernos de Saúde Pública, v. 19, n. 2, Rio de Janeiro, p. 579-59, 2003.

WENDHAUSEN, Águeda; CAPONI, Sandra. O diálogo e a participação em um conselho de saúde em Santa Catarina, Brasil. Cadernos de Saúde Pública, v. 18, n. 6, Rio de Janeiro, p. 1621-1628, 2002.

WENDHAUSEN, Águeda; CARDOSO, Sandra Maria. Processo decisório e conselhos gestores de saúde: aproximações teóricas. Revista Brasileira de Enfermagem, v. 60, n. 5, Brasília, p. 579-584, 2007.

Recebido em 13/10/2008

Aprovado em 10/11/2008 